\title{
Anhydro sugars, valuable intermediates in carbohydrate syntheses
}

\author{
Wolfgang Voelter, Khalid Mohammed Khan and Mohammed Saleh Shekhani \\ Abteilung für Physikalische Biochemie, Physiologisch-chemisches Institut der \\ Universität Tübingen, Hoppe-Seyler-Straße 4, D-72076 Tübingen, Germany.
}

\begin{abstract}
The versility of the epoxyhydroxy functionlity in pyranoses is demonstrated giving access to sugar amino acids and peptides, aminodeoxy, halodeoxy, branched-chain, cyclopropanated and aziridino sugars.
\end{abstract}

\section{INTRODUCTION}

Anhydro sugars are stable intermediates with unique properties of the oxirane ring to serve, both, as a protecting group and readily accessible reaction sites which have led to their extensive exploitation in carbohydrate syntheses. Besides, they have the advantage of the ease of removal of the protection after the desired syntetic strategy has been accomplished. During the last decade, a series of communications have appeared from our laboratory making frequent use of epoxy sugars as versastile chiral synthons in the synthesis of amino sugars, sugar amino acids and peptides, cyclopropanated and branched-chain pyranosides, halodeoxy sugars and sugar esters, chiral $\gamma$-butyrolactones, dihydrofurans or polyfuctionalized tetrahydrofurans, many of which are of potential biochemical interest (1-28).

\section{RESULTS AND DISCUSSION}

\section{Syntheses involving displacements of the triflyl group in 2,3-anhydro sugars}

Trifluoromethanesulfonic acid esters are important intermediates in modern synthetic as well as mechanistic organic chemistry. Particularly the trifluromethanesulfonates, commonly refered to as triflates, have shown excellent leaving group properties and serve in numerous transformations (29). Triflate derivatives have also been used in carbohydrate chemistry (30), and we have carried out a series of reactions involving displacement of the triflate group from $\mathbf{C - 4}$ of 2,3-anhydro sugars by a wide variety of nucleophiles. The displacement reactions at this position are not only favoured by the neighbouring oxirane ring (31), but also by the favourable geometry (2). The sugar triflates are prepared from corresponding anhydro sugars by treating them with 1.1 equivalent triflic anhydride in pyridine at low temperature.

\section{Aminodeoxy sugars}

Although several types of reactions have been useful in obtaining aminodeoxy sugars, displacement processes generally have been most effective (32). Many displacement reactions, however, suffer from severe limitations (32-34) including competing elimination reactions and the inability to effect displacement in certain situations, particularly if the leaving group is attached to a secondary carbon atom. We have now determined that many of these limiting factors can be overcome by using the triflyl group which permits facile introduction of azido and amino functions at, both, primary and secondary positions. Thus, the 4-azido-4-deoxy sugars 4-6 are prepared by slow warming the solution of the triflates 1-3 in DMF with an excess of sodium azide from $-40^{\circ} \mathrm{C}$ to room temperature (2) (Scheme 1). The compounds 5 and 6 were previously prepared as described in reference (1) through the displacement of the tosyl group from $\mathrm{C}-4$ by sodium azide in DMF at $50^{\circ} \mathrm{C}$. The yields were, however, lower than those obtained from triflates. A comparative study of the leaving group capability of the triflyl and tosyl groups is made by monitoring the reaction with the help high performance liquid chromatography. The 
reaction with triflates takes $90 \mathrm{~min}$ for completion, while that with the corresponding tosylates only goes to $70 \%$ completion after $48 \mathrm{~h}$, revealing the excellent leaving group property of the triflate group. Selective hydrogenation of the azido group with platinum oxide in methanol cleanly affords the aminodeoxy sugars 7-9 respectively (2) (Scheme 1).

Our next strategy was to introduce the amino function directly at $\mathrm{C}-4$ without the intervening azide. Attempts to displace the triflyl group by sodamide in HMPA proved futile, as the strongly basic nature of the attacking nucleophile gives rise to undesirable side reactions like B-elimination and attack on the oxirane ring. The triflyl group in 1-3 can, however, be displaced by $\mathrm{NH}_{3} / \mathrm{CHCl}_{3}$ at $50^{\circ} \mathrm{C}$ after $5 \mathrm{~h}$, resulting in the aminodeoxy sugars 7-9 (5). The scope of the reaction is further demonstrated by employing 1,2:3,4-di- $O$-isopropylidene-6- $O$-triflyl- $\alpha$-D-galactopyranose, 1,2:5,6-di- $O$-isopropylidene-3$O$-triflyl- $\alpha$-D-allofuranose and 1,2:5,6-di- $O$-isopropylidene-3- $O$-triflyl- $\alpha$-D-glucofuranose for which the substitution is known to be difficult $(35,36)$. In each case, the corresponding aminodeoxy sugar is obtained in good yield. The triflyl groups at C-4 of 2,3-anhydro sugars are further activated for displacement due to the neighbouring oxirane ring and the favourable molecular geometry, allowing facile displacement by passing gaseous ammonia into acetonic solutions of $1-3$ at $-10^{\circ} \mathrm{C}$ for $1 \mathrm{~h}$, resulting in improved yields of the amines 7-9 $(5,6)$. The one step procedure is therefore markedly superior to traditional methods employing intermediate azidodeoxy sugars, particularly for the introduction of amino groups in the presence of highly reduction-sensitive functionalities (Scheme 1).

\section{Scheme 1 .}
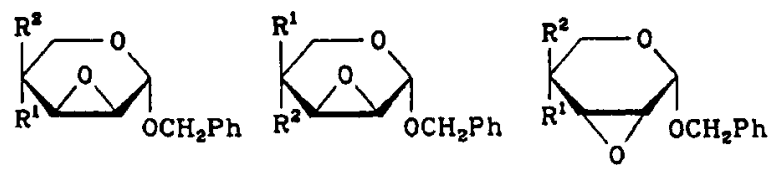

$1,4,7,10,13$

$2,5,8,11,14$

\begin{tabular}{c|cl} 
& $\mathrm{R}^{2}$ & \multicolumn{2}{l}{$\mathrm{R}^{2}$} \\
\hline $1-3$ & $\mathrm{OSO}_{2} \mathrm{CF}_{3}$ & $\mathrm{H}$ \\
$4-6$ & $\mathrm{H}$ & $\mathrm{N}_{3}$ \\
$7-9$ & $\mathrm{H}$ & $\mathrm{NH}_{2}$ \\
$10-12$ & $\mathrm{H}$ & $\mathrm{P}-\mathrm{NHC}_{6} \mathrm{H}_{4}-\mathrm{CO}_{2} \mathrm{C}^{2}\left(\mathrm{CH}_{3}\right)_{3}$ \\
$13-15$ & $\mathrm{H}$ & $\mathrm{P}-\mathrm{NHC}_{6} \mathrm{H}_{4}-\mathrm{CO}_{2} \mathrm{CCH}_{3}$
\end{tabular}

Scheme 2.

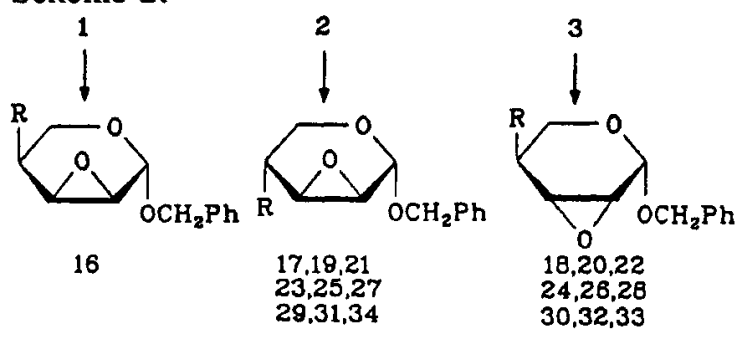

16-18: $\mathrm{R}=\mathrm{NH}-\mathrm{CH}\left(\mathrm{COOCH}_{\mathrm{p}} \mathrm{Ph}\right)-\mathrm{CH}_{3}$

19-20: $\mathrm{R}=\mathrm{NH}-\mathrm{CH}(\mathrm{COOMe})-\mathrm{CH}_{2}-\mathrm{CH}\left(\mathrm{CH}_{3}\right)_{2}$

21-22: $\mathrm{R}=\mathrm{NH}-\mathrm{CH}\left(\mathrm{COOCH}_{2} \mathrm{Ph}\right)-\left(\mathrm{CH}_{2}\right)_{4} \mathrm{NH}^{2}-\mathrm{COOCH}_{2} \mathrm{Ph}$ 23-24: $\mathrm{R}=\mathrm{NH}-\mathrm{CH}$ (COOMe) $-\mathrm{CH}_{3}$

25-26: $\mathrm{R}=\mathrm{NH}-\mathrm{CH}\left(\mathrm{COOMe}-\mathrm{CH}_{2}-\mathrm{CH}_{2}-\mathrm{S}-\mathrm{CH}_{3}\right.$

27-28: $\mathrm{R}=\mathrm{NH}-\mathrm{CH}\left(\mathrm{COOCH} \mathrm{C}_{2} \mathrm{Ph}\right)-\mathrm{CH}_{2}-\mathrm{CH}_{2}-\mathrm{COOCH}_{2} \mathrm{Ph}$ 29-30: $\mathrm{R}=\mathrm{NH}-\mathrm{CH}(\mathrm{COOMe})-\mathrm{CH}_{2} \mathrm{Ph}$

31-32: $\mathrm{R}=\mathrm{N}-\mathrm{CH}_{2}-\mathrm{CH}_{2}-\mathrm{CH}_{2}-\mathrm{CHCOOMe}$

33: $\quad \mathbf{R}=$ OH

34: $\quad \mathrm{R}=\mathrm{NH}-\mathrm{CH}\left(\mathrm{CH}_{2} \mathrm{Ph}\right)-\mathrm{CO}-\mathrm{NH}-\mathrm{CH}_{2}-\mathrm{COOCH}_{2} \mathrm{Ph}$

The foregoing strategy is also applied to comparatively weaker aromatic amines consisting of tert-butyl$p$-aminobenzoate and its methyl ester analogue. The former constitutes the essential part of highly effective folic acid which influences the formation of blood and is used with vitamin $B_{12}$ against pernicious anaemia (37). The free amino functions of both of these were utilized to cause smooth displacement of the triflyl group in 1-3 obtaining the amino sugars 10-15. The reactions were carried out in acetonitrile at room temperature in the presence of equimolar amounts of collidine. A detailed pharmocological screening of the compounds $10-15$ is presently under way and one of these (11) has already shown some antiviral activity.

\section{Sugar amino acids and sugar peptides}

From the high selectivity observed during the foregoing reactions it appears that substitution of the triflyl group in partially blocked sugar triflates by the free amino function of suitably protected naturally occuring amino acids should perform the desired $\mathrm{C}-\mathrm{N}$ coupling between two important groups of natural products, resulting in novel syntheses of a new class of pharmacologically interesting compounds. Representatives of different classes of amino acids are used to demonstrate the scope of the reaction. These include methyl esters of L-alanine, L-phenylalanine, L-leucine, L-proline or L-methionine along with the dibenzyl ester of L-glutamic acid and benzyl esters of $\mathrm{N}^{c}$-(benzyloxycarbonyl)-L-lysine and Lalanine. All of these are respectively used to displace the triflyl group in 1-3 (Scheme 2). The reactions can be carried out in DMF or acetonitrile by slowly warming from $-20^{\circ} \mathrm{C}$ to room temperature followed by stirring for further $5 \mathrm{~h}$. Besides the target compounds 16-32 (Scheme 2) which were in 
major concentration, formation of two other minor products is observed in each case. One of these was isolated pure and identified as benzyl 2,3-anhydro- $\alpha$-D-lyxopyranoside from reactions with 2 and its B-Lisomer 33 from the rection of 3 . The origin of these compounds can be explained through the competing nucleophilic displacement of the triflyl group by the moisture present in DMF or atmosphere. The same strategy can be applied for the syntheses of sugar peptides. This has been demostrated by us using Lphenylalanylglycine benzyl ester to displace the triflyl group in 2 and obtain the sugar peptides 34 (7) (Scheme 2).

\section{Fluorodeoxy sugars}

Fluorinated carbohydrates have recently gained importance due to possible applications in the insecticide and herbicide areas besides acting as inhibitors of certain enzymes (38). These are also distributed in nature in combined forms as essential parts of some highly effective antibiotics (39). The displacement reactions generally have to be carried out under forcing conditions of temperature and concentration and require strict control of the acidity of reactions to prevent elimination. A reaction which overcomes these limiting factors is the displacement of triflyl groups by fluoride ions in the neighbourhood of the oxirane ring in 1-3 (Scheme 3). Each of these was treated with tetrabutylammonium fluoride at room temperature in benzene instead of acetonitrile, whereby an appreciable decrease in reaction time along with a substantial increase in product yields was achieved. The ${ }^{1} \mathrm{H}$ and ${ }^{13} \mathrm{C} N \mathrm{NM}$ spectra of compounds 35-37 show interesting additional couplings with fluorine which are markedly dependent on their structures and conformations (40) (Scheme 3).

\section{Branched-chain sugars}

The displacement of the triflyl group with carbanions provides an approach to branched-chain sugars bearing functionalities for subsequent elaboration to compounds of biological interest. The lithium enolate of tert-butyl acetate $(41,42)$ reacts smoothly with the triflates 2 and 3 in a mixture of THF and DMSO at $-110^{\circ} \mathrm{C}$ to afford the branched-chain sugar derivatives 38 and 39 respectively (Scheme 3). Further elaboration of these compounds is in progress.

Scheme 3.
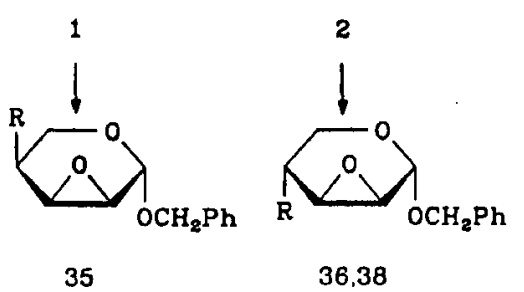

35-37: $\mathrm{R}=\mathrm{F}$

38-39: $\mathrm{R}=\mathrm{CH}_{2} \mathrm{COO}-\mathrm{C}(\mathrm{Me})_{3}$

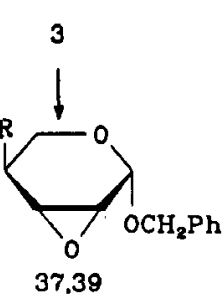

3
Scheme 4.

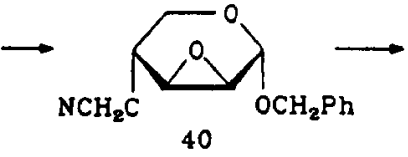

40

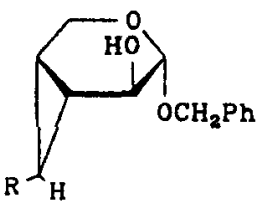

$42,44,46$

R. $\mathbf{Y}^{\mathrm{H}}$
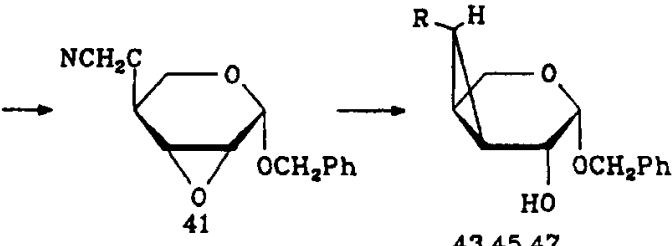

43.45 .47

42-43: $\mathrm{R}=\mathrm{CN}$

44-45: $\mathrm{R}=\mathrm{CH}_{2} \mathrm{NH}_{2}$

46-47: $\mathrm{R}=\mathrm{CH}_{2}^{2} \mathrm{NH}^{2} \mathrm{CO}-\mathrm{CH}(\mathrm{Me})-\mathrm{NH}-\mathrm{COOCH}_{2} \mathrm{Ph}$

Syntheses involving displacement and cleavage of the epoxide ring

Cyclopropanated sugars, aziridino sugars and free 3- and 4-amino acid deoxyaldopyranoses are achieved through initial displacement of the triflyl group in 1-3 by different nucleophiles, followed either by internal oxirane ring cleavage by the trans-oriented nucleophile thus introduced or by external epoxide cleavage by various reagents under acidic conditions.

\section{Cyclopropanated sugars}

If 2 and 3 are treated with the lithium salt of acetonitrile (43) in the presence of an additional equivalent of lithium diisopropylamide (LDA), the cyclopropanated sugar derivatives 42 and 43 are obtained, respectively (Scheme 4). Although a number of 2,3-cyclopropanated sugars have been described in the literature (44-47), to our knowledge these are the first examples of 3,4-cyclopropanated pyranosides. Apparently, the initially formed cyanomethyl derivatives 40 and 41 (Scheme 4) are further alkylated by 
the trans-oriented oxirane ring. In fact, all attempts to isolate 40 and 41 by performing the reaction with one equivalent of LDA, also yield 42 and 43. Thus, the transfer of a proton from 40 and 41 to the unreacted acetonitrile anion is significantly faster than the reaction of the latter with the triflate. The funtionalized cyclopropanated sugars offer an excellent opportunity for appending biologically important peptides to sugars. In order to elaborate these compounds along this line, we reduced the nitrile group of 42 and 43 with lithium aluminium hydride to the corresponding aminomethyl derivatives 44 and 45 in excellent yields (Sheme 4). The resulting amino functions were coupled with benzylocarbonyl-Lalanine to afford the amides 46 and 47 respectively (Scheme 4). The success of this reaction provides an approach towards attaching a peptide chain at this position (14).

\section{Aziridino sugars}

Aziridino sugars are important because of their biological activities. Furthermore, they are key intermediates for the introduction of a second amino functionality and a large variety of nucleophiles by way of trans-diaxial cleavage of epimine rings (48).

During the coupling of the sugars and amino acids (see above), the formation of a minor product is observed in the majority of the reactions. These are, however, formed in extremely low concentration and could only be isolated pure from the coupling reaction of the methyl ester of L-leucine and the benzyl ester of $\mathrm{N}^{\text {'}}$-benzyloxycarbonyl-L-lysine, respectively and characterized as aziridino sugars 48-51 (Scheme 5). Their formation can be rationalized by a classical intramolecular isomerization of an $\alpha$ imino oxirane into an $\alpha$-hydroxy epimine. The isomerization is jointly mediated by the trans-oriented secondary amino function and the solvent medium. Thus, in $\mathbf{3 1}$ and 32, where the nitrogen is tertiary, no isomerization is observed. Moreover, more isomerization is observed in protic solvents, particularly ethanol and methanol. It is further demonstrated by us that the aziridino sugars can be obtained as major compounds by treating an $\alpha$-imino oxirane with $\mathrm{BF}_{3}$ in ether and trimethylsilylazide. Thus, the amino sugars 11 and 12 can cleanly be converted into the corresponding aziridino sugars 52 and 53 (Scheme 5). The coordination of $\mathrm{BF}_{3}$ with the oxirane oxygen activates $\mathrm{C}-3$ towards back-side attack of the imino group, followed by hydrolysis of the intermediate $\mathrm{BF}_{3}$ adduct to provide the target componds in a single step. The reactions of both, 11 and 12, also lead consistently to the amino sugars 54 and 55 (Scheme 5). Their formation can be explained by trans-diaxial cleavage of the epimine ring by the moisture present

Scheme 5 .

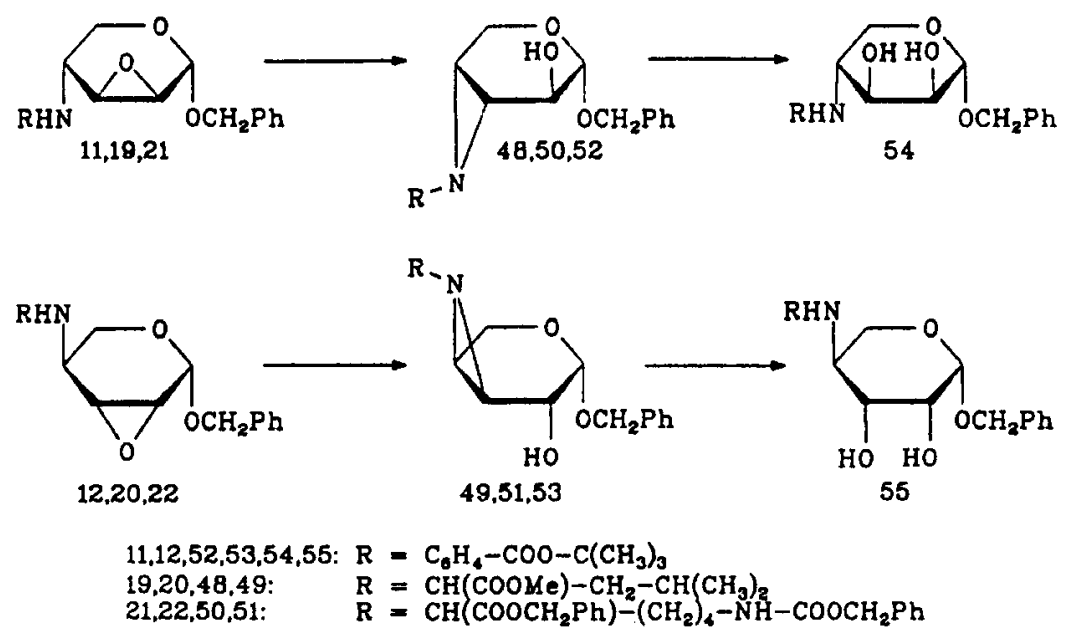

in the solvent medium and in the atmosphere. These are, however, obtained in very meagre amounts. This is the first report of the use of trimethylsilyl azide as a dipolar aprotic solvent. It imparts a greater degree of control over undesirable side reations like product hydrolysis and the participation of solvent medium in nucleophilic displacements which sometimes are encountered with DMF and acetonitrile, respectively. The conformations of the aziridino sugars 49,51 , and 53 are defined as ${ }^{\circ} \mathrm{H}_{1}$ and those of 48, 50 and 52 as ${ }^{1} \mathrm{H}_{\mathrm{o}}$ by ${ }^{1} \mathrm{H}$ NMR spectroscopy at $400 \mathrm{MHz}$. It may be stated in this context that the predominant conformation in 2,3- and 3,4-anhydropentopyranosides is the one with the glycosidic group in axial position (49). The anamoly in the compounds 48,50 and 52 is probably due to the effect of steric and electrostatic repulsion between the axial benzyloxy group and the epimine ring nitrogen in the ${ }^{\circ} \mathrm{H}_{1}$ conformation. The compounds 54 and 55 are shown to exist in the $1 \mathrm{C}$ conformation by ${ }^{1} \mathrm{H}$ NMR spectroscopic studies $(7,9,10)$. 
Free 3- and 4-amine acid deoxyaldopyrannoses

Hydrolysis of 16 with acetic acid and water $(1: 1)$ at $100{ }^{\circ} \mathrm{C}$ opens the oxirane ring diaxially; simultaneously, the ester group is hydrolyzed yielding compounds 56 and 57 , the former being the main product. A similar reaction with 17 provides 58 and 59 respectively. On the other hand, treatment of 17 with weak acids in protic solvents leads to the aziridino sugar 60. A similar product is obtained in remarkable amount by chromatography of 17 over silica gel. The stable conformation of 17 is ${ }^{\circ} \mathrm{H}_{5}$, which changes into ${ }^{3} \mathrm{H}_{\mathrm{o}}$ during the reaction to generate an axial imino group in the neighbourhood of the oxirane ring, to promote the trans-diaxial cleavage of the latter. Acid hydrolysis of 60 under the same conditions was expected to afford 61 as major compound on the basis of trans-diaxial ring opening, but contrary to that, 62 is obtained as the main product of reaction. The stable conformation of 60 is ${ }^{1} \mathrm{H}_{0}$ due to diaxial interaction between the anomeric benzyloxy group and the nitrogen of the epimine ring. However, in acetic acid the ${ }^{\circ} \mathrm{H}_{1}$ form dominates due to the possibility of hydrogen bonding between the benzyloxy group and the proton attached to the nitrogen in acidic medium. Diaxial addition of water predominantly furnishes 62 , resulting in an overall migration of the amino acid residue from $\mathrm{C}-4$ to $\mathrm{C}-3$ $(7,10$, Scheme 6).

\section{Scheme 6.}

16

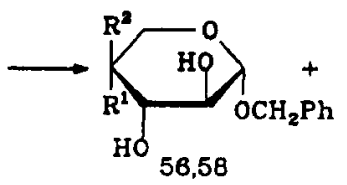

56.57: $\mathrm{R}^{1}=\mathrm{H} . \mathrm{R}^{2}=\mathrm{NH}-\mathrm{CH}\left(\mathrm{CH}_{3}\right)-\mathrm{COOH}$

58,58: $\mathrm{R}^{1}=\mathrm{NH}-\mathrm{CH}\left(\mathrm{CH}_{3}\right)-\mathrm{COOH}, \mathrm{R}^{2}=\mathrm{H}$
Scheme 7.

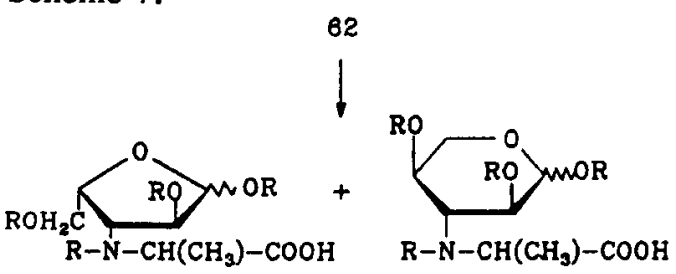

63: $R=H$

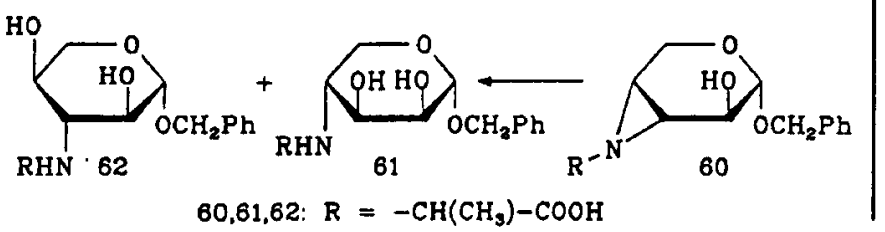

Hydrogenolysis of 62 over 10\% palladium-charcoal in methanol yields an unstable hygroscopic product comprising of anomeric mixtures of furanoside and pyranoside forms (63). Silylation of 63 with $\mathrm{N}$ methyl-N-(trimethylsilyl)trifluoroacetamide and gas chromatography of the silylated product 64 shows four peaks of $\alpha$-, $B$ - anomers of furanoside and pyranoside forms, respectively, in the intensity ratio of 1:1.2:11:12 (10, Scheme 7).

The acid hydrolysis of 18 proceeds much faster than that of 16. Instead of the expected products 56 and 57 , which would result from a direct epoxide opening of 18, the compound 66 is obtained as major product $(35 \%)$ and 67 as minor product $(6 \%)$. Their formation can be rationalized through the isomerization of 18 into its epimine 65 which prefers ${ }^{\circ} \mathrm{H}_{1}$ conformation and the acidic epimine opening takes place trans-diaxially in accordance with the Fürst and Plattner rule. Catalytic hydrogenation of 67 in water/methanol yields 68 quantitatively as a colourless solid, stable at $-20^{\circ} \mathrm{C}$. The ${ }^{1} \mathrm{H}$ NMR of 68 shows only the signals of the two pyranose isomers (13, Scheme 8$)$.

Scheme 8.

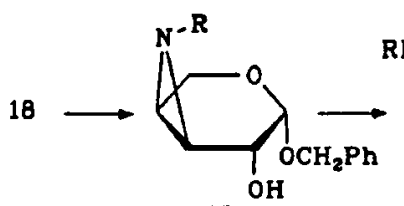

65

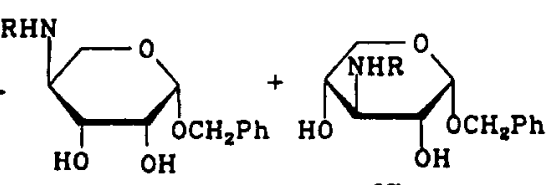

66

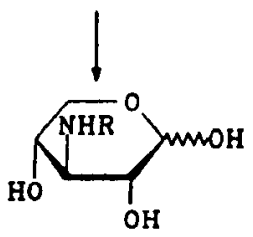

68 


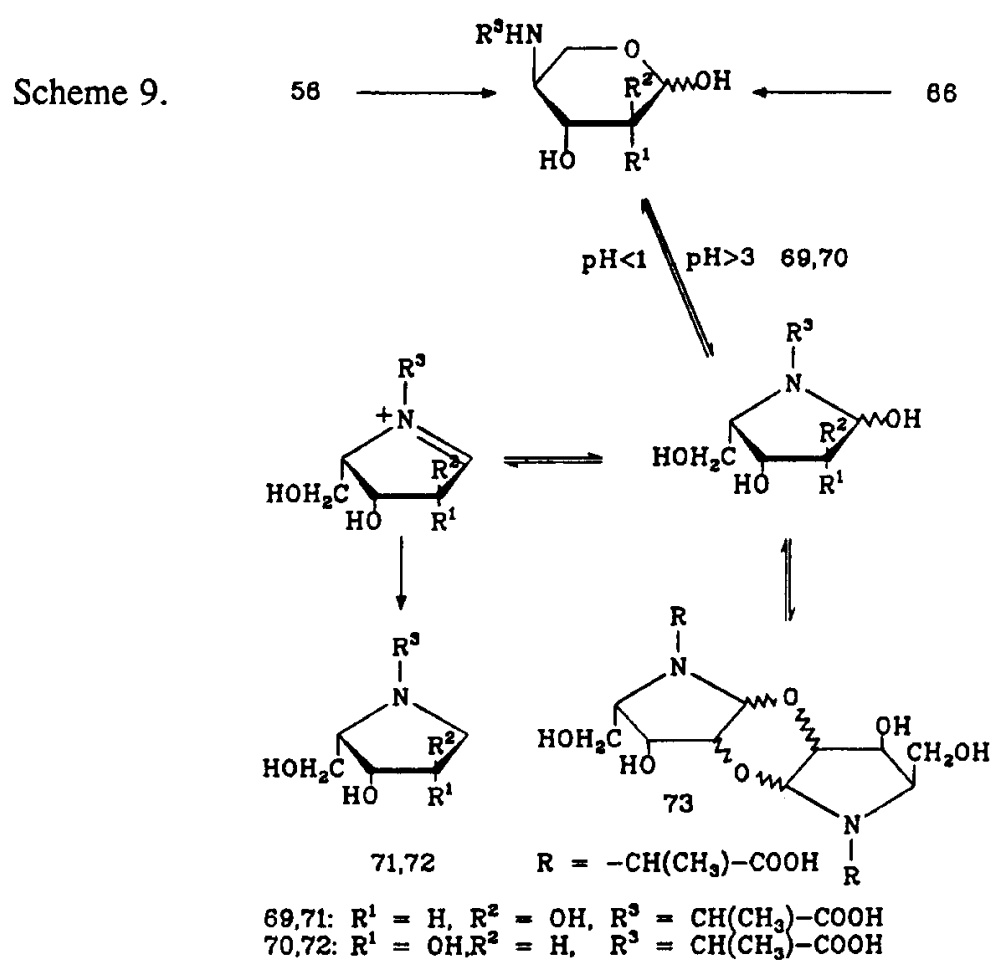

Catalytic hydrogenation of 56 respectively 66 under the same conditions as described for 67 results in the formation of 1-L-alanino-1,4-anhydro-1-deoxy-L-xylitol (71) and respectively its lyxitol isomer 72 instead of the expected 69 and 70 respectively $(13,50,51)$. The latter are in fact observed as intermediates which further react to yield $\mathbf{7 1}$, respectively $\mathbf{7 2}$. Only under strong acidic conditions (dilute sulphuric acid) can the nucleophilicity of the nitrogen be sufficiently reduced to suppress the formation of fivemembered rings. The free 69 and 70 can then be liberated by addition of a sufficient amount of barium hydroxide to precipitate all sulphate ions. Extensive ${ }^{1} \mathrm{H}$ NMR investigations at different $\mathrm{pH}$ values prove that 69 and 70 prefer pyranose forms at acidic $\mathrm{pH}$ while the pyrrolidine and bis(pyrrolidine) (73) forms start to dominate at basic $\mathrm{pH}$. Further studies are underway to investigate the biological properties of the described conjugates of sugars and amino acids, which so far have not been obtained from natural sources $(13$, Scheme 9$)$.

\section{CONCLUDING REMARKS}

The syntheses, surveyed in this article, demonstrate that epoxytriflate pyranoses are versatile synthons for numerous transformations of the starting carbohydrates into e.g. aminodeoxy, halodeoxy, cyclopropanated, branched-chain sugars or new classes of sugar amino acids and peptides. Due to preliminary studies, quite a few of these now accessible compounds seem to have effects on the immune systems or antibacterial activities and far some selected candidates potential drug development is in progress.

\section{REFERENCES}

1. N. Vethaviyasar, R. Kimmich and W. Voelter. Chemiker Zeitung 101, 36 (1977).

2. R. Kimmich and W. Voelter. Liebigs Ann. Chem. 1100 (1981).

3. N. Afza, A. Malik and W. Voelter. Chimia 37, 422 (1983).

4. A. Malik, W. Kowollik, P. Scheer, N. Afza and W. Voelter. J. Chem. Soc. Chem. Commun. 1229 (1984).

5. A. Malik, N. Afza, M. Roosz and W. Voelter. J. Chem. Soc. Chem. Commun. 1530 (1984).

6. A. Malik, M. Roosz and W. Voelter. Z. Naturforsch. 40b, 559 (1985).

7. W. Kowollik, A. Malik, N. Afza and W. Voelter. J. Org. Chem. 50, 3325 (1985).

8. N. Afza, A. Malik, F. Latif and W. Voelter. Liebigs Ann. Chem. 1929 (1985).

9. F. Latif, A. Malik and W. Voelter. Liebigs Ann. Chem. 717 (1987). 
10. W. Kowollik, G. Janairo and W. Voelter. Liebigs Ann. Chem. 427 (1988).

11. W. Kowollik and W. Voelter. Liebigs Ann. Chem. 433 (1988).

12. M.S. Shekhani, F. Latif, A. Fatima, A. Malik and W. Voelter. J. Chem. Soc. Chem. Commun. 1419 (1988).

13. W. Kowollik, G. Janairo and W. Voelter. J. Org. Chem. 53, 3943 (1988).

14. A. Fatima, F. Zaman, M.S. Shekhani, A. Malik and W. Voelter. Liebigs Ann. Chem. 389 (1990).

15. F. Latif, M.S. Shekhani and W. Voelter. J. Chem. Soc. Perkin Trans. 11573 (1990).

16. W. Kowollik and W. Voelter. Z. Naturforsch. 47b, 589 (1992).

17. T.H. Al-Tel, Y. Al-Abed, M.S. Shekhani and W. Voelter. Tetrahedron Lett. 34, 7717 (1993).

18. Y. Al-Abed, T.H. Al-Tel and W. Voelter. Tetrahedron 49, 9295 (1993).

19. Y. Al-Abed, T.H. Al-Tel and W. Voelter. Nat. Prod. Lett. 4, 73 (1994).

20. T.H. Al-Tel, Y. Al-Abed and W. Voelter. J. Chem. Soc. Chem. Commun. 1735 (1994).

21. S.N. Kazmi, Z. Ahmed, A. Malik, N. Afza and W. Voelter. Z. Naturforsch. 50b, 294 (1994).

22. J. Tschakert and W. Voelter. Z. Naturforsch. 49b, 702 (1994).

23. F. Zaman, A. Fatima, A. Malik and W. Voelter. Z. Naturforsch. 49b, 1434 (1994).

24. T.H. Al-Tel, R.A. Al-Qawasmeh, C. Schröder and W. Voelter. Tetrahedron 51, 3141 (1995).

25. M.H. Abu Zarga, T.H. Al-Tel and W. Voelter. Z. Naturforsch. $50 \mathrm{~b}, 697$ (1995).

26. T.H. Al-Tel and W. Voelter. Tetrahedron Lett. 36, 523 (1995).

27. T.H. Al-Tel, R.A. Al-Qawasmeh, T. Kaiser and W. Voelter. Tetrahedron Lett. 36, 4599 (1995).

28. T.H. Al-Tel, M. Meisenbach and W. Voelter. Liebigs Ann. Chem. 689 (1995).

29. P.J. Stang, M. Hanack and L.R. Subramanian. Synthesis 85 (1982).

30. R.W. Binkkley and M.G. Ambrose. J. Carbohydr. Chem. 3, 1 (1984).

31. A. Rosowski. In: A. Weissberger, (Ed.), Heterocyclic Compounds with Three- and FourMembered Rings, Part III, Interscience Publishers, New York (1964).

32. D. Horton and J.D. Wander. In: W. Pigman and D. Horton (Eds), The Cabohydrates, Chemistry and Biochemistry, Vol. IB, p.726, Academic Press, New York (1980).

33. K. Freudenberg and R.M. Hixon. Chem. Ber. 56, 2119 (1923).

34. W.M. Corbett. J. Chem. Soc. 2926 (1961).

35. K. Freudenberg, O. Burkhart and E. Braun. Chem. Ber. 59, 714 (1926).

36. U.G. Nayak and R.L. Whistler. J. Org. Chem. 34, 3819 (1968).

37. S.H. Pine, J.B. Handrickson and D.J. Cram, Organic Chemistry, Ed. 4, p. 354, McGraw Hill Co., New York (1980).

38. P.W. Kent. Chem. Ind. Rondon) 1128 (1969).

39. G.O. Morton, J.E. Lancaster, G.E. Van Lear, W. Fulmor and W. E. Meyer. J. Am. Chem. Soc. 91, 1535 (1969).

40. F. Latif, A. Malik and W. Voelter. Liebigs Ann. Chem. 617 (1987)

41. M.W. Rathke and A. Lindert. J. Am. Chem. Soc. 93, 2318 (1971).

42. W. Bos and H.J.H. Pabon. Rec. Trav. Chim. Pays-Bas 99, 141 (1980).

43. S. Arseniyadis, K. S. Kyler and D.S.Watt. Org. React. 31, 1 (1984).

44. W. Meyer zu Reckendorf and U. Kamprath-Scholtz. Chem Ber. 105, 673 (1972).

45. B. Fraser-Reid and B.J. Carthy. Can. J. Chem. 50, 2928 (1972).

46. B. Fraser-Reid, N.L. Holder, D. R. Hicks and D.L. Walker. Can. J. Chem. 55, 3978 (1977).

47. S.Y.-K. Tam and B. Fraser-Reid. Can. J. Chem. 55, 3996 (1977).

48. A.R. Katritzki and C. W. Rees, Comprehensive Heterocyclic Chemistry, Small and Large Rings, Vol. 7, Pergamon Press, Oxford (1984).

49. E.L. Eliel, N.L. Allinger, S.J. Angyal and G.A. Morrison, Conformational Analysis, p. 357, Interscience, New York (1965).

50. H. Paulsen, G. Landsky and H. Koebernick. Chem. Ber. 111, 3699 (1978).

51. W. Meyer zu Reckendorf and N. Wassiliadou-Micheli. Chem Ber. 107, 1188 (1974). 